УДК 610.1/19(107)

\title{
ВЛИЯНИЕ ТРУДОВОГО ПОТЕНЦИАЛА В МОДЕЛИ РАСПРЕДЕЛЕНИЯ РЕСУРСОВ В УКРАИНЕ
}

Д-р экон. наук А.Г. Дейнека, канд. экон. наук В.А. Котик

\section{ВПЛИВ ТРУДОВОГО ПОТЕНЦІАЛУ В МОДЕЛІ РОЗПОДІЛУ РЕСУРСІВ В УКРАЇНІ}

Д-р екон. наук О.Г. Дейнека, канд. екон. наук В.О. Котик

\section{INFLUENCE OF WORKING POTENTIAL IN THE MODEL OF THE DISTRIBUTION OF RESOURCES IN THE UKRAINE}

Dr. of econ. sciences Olexander Dejneka, cand. of econ. sciences Valentina Kotik

В порядку обговорення запропоновано використання емпіричних моделей (витрати-випуск) для планування народного господарства. Розглянуто критеріі оптимальності та обмеження. Проаналізовано механізм життєздатності моделі щзодо оцінки та прогнозування роботи залізничного транспорту та його сочіальної сфери.

Ключові слова: емпірична модель, модель лінійного програмування, критерій оптимальності, кваліфікація, робоча сила, витрати на робочу силу, конкуруючий імпорт, макроекономічний прогноз, ефективність економіки Украӥни.

В порядке дискуссии предлагается возможность использования эмпирической модели (затраты-выпуск) для планирования национальной экономики. Рассмотрены критерии оптимальности и ограничения. Проанализирован механизм жизнеспособности модели при оченке и прогнозировании работы железнодорожного транспорта и его социальной сферы. 
Ключевые слова: эмпирическая модель, модель линейного программирования, критерий, оптимальность, квалификачия, рабочая сила, затратьл труда, конкурирующий импорт, макроэкономическое прогнозирование, эффективность экономики Украины.

In a number of the countries was carried out a large quantity of issledova of niy, directed toward the development of the models of linear by programmi of rovaniya for purposes of planning. Some of these of issledova of niy are well known and was reflected in the economic literature. However, in the Ukraine until recently the attempts to use this approach to the planning it was not done. By way of discussion the possibility of using the empirical model (expenditure- release) for planning the national economy is proposed. The criteria of optimality and limitation are examined. The mechanism of the viability of model during estimation and prognostication of rail transport and social sphere is analyzed.

The keywords: empirical model, the models of linear by programmi of rovaniya, criterion, optimality, qualification, work force, labor input, the competitive import, macroeconomic prognostication, effektivnost of the economy of the Ukraine.

Введение. В ряде стран было проведено большое количество исследований, направленных на разработку моделей линейного программирования для целей планирования. Некоторые из этих исследований хорошо известны и получили отражение в экономической литературе. Однако в Украине до последнего времени попыток использовать такой подход к планированию не делалось. В настоящей статье описывается опыт разработки модели типа «затраты - выпуск» для экономики Украины.

Определение цели и задачи исследования. Исследование имело целью установить возможность создания эмпирической модели, полезной для планирования украинской (или подобной ей) экономики на основе доступных в настоящее время информации и вычислительных методов.

Постановка проблемы в общем виде и ее связь с важными научными и практическими задачами. Для того чтобы получить представление об экономической системе, для описания которой используется модель, остановимся вкратце на некоторых особенностях украинской экономики.

В последнее десятилетие многие ученые занимались проблемами экономики железнодорожного транспорта [1-11], экономикой и менеджментом [9], финансовым менеджментом [8], управлением людскими ресурсами [7,6], вопросами особенности подготовки квалифицированных кадров [5], эндогенными переменными и их ролью в программировании [4], проблемой занятости и платежного баланса на транспорте [3], критериями оптимальности в исследовании [2], возможности снижения убыточности перевозок [7], поскольку часть валового национального продукта страны направлялась на капиталовложения. Но этого оказалось недостаточно для осуществления таких структурных изменений, которые позволили бы снять с повестки дня проблемы занятости и платежного баланса. Если к тому же учесть еще наличие ряда других региональных проблем, то становится понятным стремление так распределить ресурсы, чтобы были обеспечены соответствующие структурные сдвиги, позволяющие в будущем полностью решить или, по крайней мере, смягчить указанные проблемы. На достижение данной цели и была направлена рассматриваемая ниже модель.

В качестве критерия оптимальности модели был выбран максимум уровня личного потребления, достигаемый к некоторому моменту времени $T$ при условии выполнения ограничений, описывающих структуру экономики Украины.

Основная часть исследования. Для включения в модель были отобраны шесть дорог железнодорожного транспорта. Ее эндогенные переменные охватывают 34 переменные перевозки товаров собственного производства по этим дорогам, 33 переменные экспорта, 33 переменные импорта (с делением на группы «конкурирующего» и дополняющего импорта, на приросты валового капитала по отраслям и на личное потребление). К экзогенным переменным модели относятся общественное потребление, труд и агрегированный основной капитал.

Модель имеет ряд ограничений, к которым, прежде всего, относится ограничение 
по потокам продуктов. Оно может быть записано следующим образом:

$$
(1-A) X-B-E-C+M \geq G,
$$

где $(1-A)$ - матрица Леонтьева $(A-$ матрица коэффициентов затрат системы «затраты выпуск», характеризующих затраты на единицу продукции конкретной отрасли);

$X$ - вектор предложения железнодорожного транспорта;

$B$ - матрица валовых приростов основного капитала по дорогам;

$E$ - матрица, на главной диагонали которой находятся показатели экспорта по отраслям, а остальные элементы равны нулю;

$M$ - матрица, на главной диагонали которой находятся показатели «конкурирующего» импорта по отраслям, а остальные элементы равны нулю;

$G$ - вектор общественного потребления.

В зависимости от квалификации (или уровней образования) рабочая сила в модели делится на две категории. В первую категорию включены промышленные и сельскохозяйственные рабочие, а во вторую служащие. Для труда были использованы следующие ограничения:

$$
W X \leq L
$$

где $W$ - матрица коэффициентов затрат труда с размерами $2 \mathrm{X} 34$;

$\mathrm{L}$ - вектор с размерами $2 \mathrm{X} 1$ доступных трудовых ресурсов.

Поскольку считалось, что на структурные изменения в экономике Украины за период (от 5 до 10 лет) существенное влияние оказывает величина уже имеющегося основного капитала, в модель было введено следующее ограничение:

$$
\sum_{j} R_{j} x_{j} \leq K
$$

где $k j-$ капитал, используемый на производство единицы $j$-го продукта; $K-$ величина существующего основного капитала. Как и другие экзогенные переменные, величина $K$ должна быть спрогнозирована на расчетный год $T$.

Кроме того, модель содержит ограничение по внешней торговле

$$
\sum_{j} m_{j}^{m c}+\sum_{j} m_{j}^{c}+\sum_{j} e_{j} \leq D
$$

где $\sum_{j} m_{j}^{m c}-$ «неконкурирующий» импорт в j-ю отрасль; $\sum_{j} m_{j}^{c}, \quad-$ «конкурирующий» импорт в $j$-ю отрасль; $e$,-экспорт продукции $j$ й отрасли; $D$ - заданная величина желаемого баланса текущих платежей (это тип целевой переменной, являющейся заданной экзогенной константой для различных экспериментальных расчетов). От всех эндогенных переменных модели требовалось, чтобы они были неотрицательными.

Перечисленные ограничения характеризуют первую, базисную, модификацию эксперимента, проведенного с помощью рассматриваемой модели. Две другие его модификации осуществлялись при дополнительных ограничениях. Для второй модификации было добавлено следующее ограничение:

$$
x_{j} \leq(-M) \bar{X}_{j},
$$

где $M$ - доля основного капитала, амортизируемая за плановый период; $\bar{X}$ i величина $x_{j}$ в базисный год (2014 г.).

В третью модификацию, кроме этого ограничения, было введено такое лимитирующее условие:

$$
\mathrm{e}_{j} \leq E_{j}, \mathrm{j}=1,2, \ldots ., \mathrm{n},
$$

где $E_{j}-$ ожидаемый максимум экспортных поставок ј-й отрасли в расчетный год. В следующем разделе мы приведем соображения, которые объясняют использование различных типов ограничений.

Хорошо известно, что в задачах с конечным горизонтом планирования определенное внимание должно уделяться развитию экономики Украины за пределами планового периода. Это достигается путем учета в модели прироста основного капитала в плановом периоде. Но предварительно надо решить, каким образом ввести в модель формирование основного капитала. 
Для того чтобы превратить валовой прирост основного капитала в эндогенный фактор, мы сделали простое допущение

$$
B=F(X),
$$

где $F(X)$ - линейная функция. Если матрицу результирующих вложений «отрасль на отрасль» обозначить через $K$, то искомое отношение будет иметь вид

$$
B=K X \text {. }
$$

Теоретическим обоснованием отношения такого типа служит соображение, что $X$ характеризует возможности финансирования капиталовложений. Это соотношение вполне пригодно для определения направлений вложений при среднесрочном планировании.

Обсуждение сформированной модели. Выбор потребления в качестве максимизируемой переменной величины основан на допущении о существовании некоторой функции полезности экономики $U=U(C)$, где $\mathrm{U}$-уровень полезности, а $\mathrm{C}$ потребление. Такое допущение соответствует традиционному подходу экономистов, в частности, оно используется в работах по теории оптимальности роста экономики. Указанный подход предполагает, что благосостояние общества представляет собой функцию уровня его потребления. Эта отправная посылка в последнее время подвергается очень сильной критике, но ее применение исходит из идеи, что наиболее существенным элементом при анализе благосостояния является все же потребление.

Мы в качестве оптимизируемой переменной выбрали уровень личного потребления. Одно из преимуществ такого подхода заключается в его простоте. Тем не менее, надо помнить о явной ограниченности этого подхода с точки зрения теории благосостояния. По нашему мнению, совершенная модель должна основываться на более широком взгляде на цели общества по сравнению с рассмотрением уровня потребления в том виде, в каком он сегодня измеряется в национальном бюджете. При введении ограничений (1) анализ начинается с допущения, что перераспределение ресурсов может осуществляться главным образом путем замещения «конкурирующего» импорта местным производством или наоборот. В данной связи импорт делится на «конкурирующий» и дополняющий. При этом предполагается, что последний является линейной функцией общего объема производства соответствующей отрасли и что его замещение невозможно. Разумеется, это предположение означает упрощение реального положения, поскольку отнюдь не весь дополняющий импорт относится к продуктам, которые не могут быть произведены внутри страны.

При избранном нами подходе коэффициенты затраты-выпуск определены таким образом, что включают затраты как местного производства, так и «конкурирующего» импорта, причем замещение продуктов этих двух групп не ограничивается. Иными словами, весь «конкурирующий» импорт может быть замещен местными продуктами, и наоборот.

В ограничениях (2) труд подразделен на две категории. В первую из них включается менее образованная рабочая сила — рабочие, фермеры и сельскохозяйственные рабочие (первая составляет в Украине значительную часть трудовых ресурсов). Вторая категория в принципе должна охватывать более образованных работников. Практическое разделение рабочей силы на две указанные категории в ряде случаев сопряжено с определенными затруднениями.

Ограничения (3) и (5) принимают в расчет существующий основной капитал и скорость, с которой он может быть перераспределен. Капитал представляет собой фактор, который необходимо учитывать при рассмотрении структурных изменений. Ограничение (5) означает, что производство в той или иной отрасли максимально может быть уменьшено на величину, определяемую темпом амортизации ее капитала. Мы допускаем, что такая оценка несколько преувеличивает возможности этих изменений, поскольку расчеты темпа амортизации основываются на тех ее нормах, которые принимаются, исходя из коммерческих соображений. Но отсюда следует, что в ряде случаев полностью амортизированный основной капитал может обеспечивать известные производственные мощности.

Данные для рассматриваемой модели были получены в основном в результате 
исследования затрат и выпуска в экономике Украины в 2014 г.

Хотя в последнее время значительно усилилось внимание $к$ разработке динамических моделей макроэкономического прогнозирования, тем не менее, надо сказать, что и статические модели обладают определенными достоинствами. Во-первых, они отличаются простотой, вследствие чего анализ легче начинать именно с таких моделей. Во-вторых, они в большей мере обозримы, нежели динамические модели, которые обычно весьма громоздки, трудно поддаются интерпретации и отнюдь не гарантируют от непрослеживаемых ошибок. В-третьих, статические модели, требуя значительно меньшего объема информации, в то же время могут дать полезную информацию о функционировании экономики. В-четвертых что, по мнению авторов, наиболее важно, надо считаться с трудностями количественного прогнозирования технологических изменений и тех эффектов, которые эти изменения оказывают на коэффициенты затраты-выпуск, даже при среднесрочном анализе. Однако имеются свидетельства, что указанные коэффициенты могут оставаться достаточно стабильными на протяжении периода порядка двух-пяти лет. При более же широких горизонтах планирования целесообразно, вероятно, использовать значительно агрегированные модели.

Наконец, нельзя упускать из виду еще одно важное обстоятельство, говорящее в пользу избранного нами подхода. В последние годы методы, применяемые в экономическом анализе, заметно улучшились. Кроме того, благодаря развитию компьютерной техники они стали практически реализуемыми. Это открыло возможности для эмпирического исследования различных проблем оптимизации, которые до сих пор в большей части поддавались лишь теоретическому анализу.

Цель проводимых нами экспериментов заключалась в оценке величин переменных модели на 2020 г. Базисным был избран 2014 г. Мы полагаем, что пятилетний период планирования в наибольшей степени подходит для рассматриваемого типа моделирования.

Для разработки плана на 2020 г. потребовался соответствующий прогноз экзогенных переменных. Он был получен главным образом на основе поведения этих переменных в прошлом. Трудовые ресурсы на 2020 г. оценивались в единицах «эффективности» (произведения фактической численности рабочей силы на оцененное изменение производительности).

При оценке количества эффективного труда было сделано допущение, что темпы роста производительности труда сохранятся на уровне, достигнутом за последние 10 лет. Переменная баланса текущих платежей относится к типу политических целевых переменных, что немаловажно в существующей нестабильной социально-экономической ситуации в Украине и в мире в целом. В основных модификациях модели требовалось, чтобы она была равна нулю (т. е. чтобы текущие платежи были сбалансированы).

Первые экспериментальные расчеты были проведены по трем основным модификациям модели, характеризующимся следующими особенностями.

В первой модификации отсутствуют ограничения, налагаемые на движение капитала и труда между отраслями и на экспорт продукции. Иными словами, в наиболее простом случае допускается, что иностранные рынки могут поглотить все предложенное (при одних и тех же условиях) количество различных продуктов. Это означает, что рассматриваемая страна является столь малым поставщиком на мировой рынок, что ее предложение не влияет на его цены. Применительно к большинству продуктов украинского экспорта такое допущение довольно близко к реальности. Имеется лишь несколько видов продукции, значительное увеличение предложения которых со стороны Украины может оказать заметное воздействие на цены мирового рынка.

Во вторую модификацию модели вводятся ограничения на движение существующего капитала между отраслями. Допускается, что объем капитала в секторе может уменьшиться только в результате амортизации. Это также ограничивает сокращение объема производства в секторах экономики. Максимальное потребление капитала в отрасли определяется кумулятивной амортизацией за пятилетний период. В этой модификации модели отсутствует ограничение по расширению экспорта. 


\section{Експлуатація залізниць}

Выводы из исследования и перспективы, дальнейшее развитие в данном направлении. Поскольку трудно ожидать, что линейные функции экспорта останутся неизменными при любом предложении, в третью модификацию модели в дополнение к ограничениям второй модификации вводятся ограничения на расширение. Мы полагаем, что анализ всех трех модификаций модели и сравнение полученных с их помощью результатов имеет, по крайней мере, теоретический интерес. Посредством такого анализа мы надеялись получить определенное представление об эффективности различных отраслей и экономики Украины в целом.

\section{Список использованных источников}

1. Цимбалюк, Г. Критерии оптимальности в исследовании [Текст]: учебник / Г. Цимбалюк. М.: Наука, 2005. -351 с.

2. Соловьев, С.Г. О проблеме занятости и платежного баланса на транспорте [Текст]: монография / С.Г. Соловьев. - М.: Мысль, 2009. - 408 с.

3. Бондаренко, С.В. Эндогенные переменные и их роль в программировании [Текст]: учебник / С.В. Бондаренко. - К.: Думка, 2011. - 253 с.

4. Дейнека, А.Г. Особенности подготовки квалифицированных кадров [Текст] / А.Г. Дейнека // Вестник ХГУ. - 2009. - № 758. - С.49-56.

5. Основні норми положення 3 технічного нормування праці на залізничному транспорті [Текст]: зб. для практичного використання. - К.: Укрзалізниця, 2004. - 203 с.

6. Красношапка, В.В. Управління людськими ресурсами [Текст]: курс лекцій для спеціальності "Адміністративний менеджмент". - К.: КНЕУ, 2004. - 197 с.

7. Жуков, В.А. Возможности снижения убыточности пригородных перевозок [Текст] / В.А. Жуков // Железнодорожный транспорт. - 2003. - №7. - С. 29-30.

8. Фінансовий менеджмент [Текст]: навч.-метод. посібник для самостійного вивчення дисципліни. - К.: КНЕУ, 2001. - 296 с.

9. Економіка та менеджмент [Текст]: навч. посібник. - Львів: Державний університет «Львівська політехніка», 1996. - 828 с.

10.Положення про організацію нормування праці на залізничному транспорті [Текст]: офіційне видання. - К.: Укрзалізниця, 2011.-163 с.

Дейнека Олександр Георгійович, д-р екон. наук, професор, завідувач кафедри менеджменту і адміністрування Українського державного університету залізничного транспорту. Тел. (057) 730-10-46. E-mail: dejneka@list.ru. Котик Валентина Олексіївна, канд. екон. наук, доцент. Тел. (057) 730-19-72. E-mail: ukrdaztezt@mail.ru.

Dejneka Oleksandr Heorgiyovich, Dr. of econ. sciences, professor, head of department of management and administration Ukrainian State Universiteta of Railway Transport. Tel. (057) 730-10-46 E-mail: dejneka@list.ru. Valentina Kotik, cand. of econ. sciences, associate Professor, Tel. (057) 730-19-72. E-mail: ukrdaztezt@mail.ru.

Наукова праця здана до друку 20.07.2015 року 